\title{
Dry Socket: Frequency, Clinical Picture, and Risk Factors in a Palestinian Dental Teaching Center
}

\author{
Mohammed H. Abu Younis and Ra'ed O. Abu Hantash* \\ Al Quds University, Jerusalem, Palestine \\ Department of Prosthodontics, Al Quds University, Jerusalem, Palestine
}

\begin{abstract}
Aims: The objectives of this study were to find out the frequency, clinical picture, and risk factors of dry socket at the Dental Teaching Center of Al-Quds University in Palestine.

Methods and Materials: Two previously used questionnaires were accomplished in this study over a one year period. The first questionnaire was completed for every patient who had one or more permanent teeth extracted in the Dental Surgery Clinic. The other one was completed for every patient suffered a postoperative pain and was diagnosed with dry socket.

Results: There were 1305 dental extractions performed in 805 patients. The overall frequency of dry socket was $3.2 \%$. The incidence of dry socket following non-surgical extractions was $1.7 \%$ while it was $15 \%$ following surgical extractions $(\mathrm{P}<0.005)$. The incidence of dry socket was significantly higher in smokers $(12 \%)$ than in non-smokers $(4 \%)(\mathrm{P}<0.005)$, however, there is a strong association between the amount of smoking and the incidence of dry socket $(\mathrm{P}<0.002)$. The incidence of dry socket was significantly higher in the single extraction cases (13\%) than in the multiple extraction cases $(5 \%)(\mathrm{P}=0.005)$. Age, sex, medical history, extraction site, amount of local anesthesia and experience of operator play no role in the occurrence of dry socket.

Conclusion: Smoking, surgical trauma and single extractions are considered predisposing factors in the occurrence of dry socket. On the other hand, factors like: age, sex, medical history, extraction site, amount of anesthesia, and operator experience have no effect on the observation of dry socket.
\end{abstract}

Keywords: Dry socket, prevalence, smoking, surgical extraction.

Dry socket is one of the most common complaints the patient suffers following dental extraction. It is more frequent following mandibular third molar extraction [1-7]. The literature shows variation in its incidence. Petri and Wilson (1992) [8] reported a 0\% incidence while Erickson et al. (1960) [9] reported an incidence of $35 \%$. Dry socket occurs due to the disintegration of the blood clot by fibrinolysis [10]. Many factors contribute to the occurrence of dry socket. For example: low experience level of operator $[2,6]$ preoperative infection $[10,11]$, sex [10,12], site of extraction [6,12], use of oral contraceptives [13], smoking [14], and use of local anesthetics with vasoconstrictor [15]. The incidence of dry socket can be reduced through the use of antibiotics [16,17], antifibrinolytic agents [18], mouthwashes [19-21], steroids [22] and intra-alveolar medicaments [7]. The management of dry socket includes reassurance of the patient, irrigation, and placement of intra-alveolar dressing [9, 22-24].

This is the first study of dry socket at the Dental Teaching Center of Al-Quds University in Palestine. Its aims were to find out the frequency, clinical picture and risk factors at this Palestinian dental teaching center.

*Address correspondence to this author at the Department of Prosthodontics, Al Quds University, Jerusalem, Palestine; Tel: 009722 2791065; Fax: 009722 2791065; E-mail: abuhantash@yahoo.com
It does worth to mention that this study was totally observational without any interference with any of the clinical procedures normally followed at this center.

\section{Description of the Study}

During this study, 1305 permanent tooth extractions were performed in 805 patients. There were 467 (58\%) male patients and $338(42 \%)$ female patients. The age of patients ranged from 10 to 73 years with a mean of $35.4( \pm 14.95)$ years.

The Dental Teaching Clinics of Al Quds University was the setting of the study. These Clinics are located in Abu Dies besides Eastern Jerusalem in Palestine (West Bank), and are involved in the training of undergraduate dental students. It serves the community of Eastern Jerusalem and its neighboring towns and villages, which have a total population of around 500,000.

The study was totally observational, without any interference with treatment protocols followed at the dental teaching Clinics of Al Quds University.

Data were collected over a period of 16 months, from October $1^{\text {st }} 2006$ to January $28^{\text {th }} 2008$ using two questionnaires. The first one was completed for every patient who had one or more permanent teeth extracted in the Dental Surgery Clinic. Patients who had only deciduous teeth extracted were excluded from the study. The questionnaire was 
filled by the person who did the extraction. It included items such as patients' personal data, smoking habits, medial history and medications, teeth extracted indication for extraction, level of experience of the operator who performed the extraction, amount and technique of local anesthesia, and postoperative medications. Features of third molar also recorded (Fig. 1).

The other one was completed for every patient suffered a postoperative pain and was diagnosed with dry socket. According to Blum's definition of dry socket [22], patients were diagnosed with a dry socket if they had at least two of the following signs and symptoms:

a. Empty socket

b. Pain in or around the socket within one week of the extraction

This questionnaire also included patients' personal data, socket affected, signs and symptoms, onset of symptoms, and given treatment (Fig. 2).
Data were analyzed using SPSS ${ }^{\circledR}$ for Windows (Version 9; SPSS Inc, Chicago, IL, USA) and Epi-info ${ }^{\circledR}$ (CDC, Atlanta, GA, USA) statistical software. Descriptive statistics and bi-variant data analysis using chi-square tests were done as appropriate. $\mathrm{P}$ value was set at 0.05 as level of significance.

\section{RESULTS}

During the study period, 1305 dental extractions were carried out in 805 patients. There were 467 (58\%) male patients and $338(42 \%)$ female patients. Age of patients ranged from 10 to 73 years with a mean of $35.4( \pm 14.95)$ years.

A total of $286(35.5 \%)$ patients were smokers, of whom 33 ( $7 \%$ of the total sample) were heavy smokers (smoked more than 20 cigarettes per day). The proportion of smokers was noticeably higher in the male group than in the female group (58\% and $3.9 \%$ respectively). Despite most of patients 566 $(70.3 \%)$ were fit and healthy at the time of extraction, 239 (29.7\%) had varying underlying systemic conditions (Table 1), and 169 (21\%) were taking different medications (Table 2).

\section{Dry sockets at the Dental teaching Hospital Extraction sheet}

Please tick all that applies:

Patient's name File number:

Date: / /

Gender: $\square$ Male $\square$ Female

Age: ........ Years

Medical History:

Medications:

Oral Hygiene: $\square$ Good (no gingival inflammation)

$\square$ Fair (Mild gingival inflammation)

Poor ( moderate or sever gingival inflammation)

Teeth extracted:

\begin{tabular}{|c|c|c|}
\hline Reasons for extraction & : $\square$ Advanced caries & $\square$ advanced periodontal disease \\
\hline & $\square$ Orthodontic & $\square$ Pericoronitis \\
\hline & $\square$ Others, specify ................ & \\
\hline Extraction technique: & $\square$ simple elevation & $\square$ Root separation \\
\hline & $\square$ Flap without bone removal & $\square$ Flap with bone removal \\
\hline Operator: & $\square 4^{\text {th }}$ year dental student & \\
\hline & $\square 5^{\text {th }}$ year dental student & \\
\hline & $\square$ consultant & \\
\hline
\end{tabular}

Number of local anesthetic cartridges

Technique of local anesthesia : $\square$ labial/ buccal infiltration

$\square \mathrm{ID} /$ lingual block

Postoperative instructions given? $\square$ yes $\square$ no

Post operative mediactions prescribed:
Lingual / palatal infiltration

$\square$ Mental block

Fig. (1). Dry sockets at the Dental teaching Hospital Extraction sheet. 
Please tick all that apply

Patient's name:

Date: / /

Gender: $\square$ Male $\square$ Female

Socket affected:

Signs and symptoms: $\square$ pain

$$
\begin{aligned}
& \square \text { Empty socket } \\
& \square \text { Bare bone } \\
& \square \text { Halitosis } \\
& \square \text { Others: ........ }
\end{aligned}
$$

\section{Dry Socket Sheet}

File number:

\section{Onset of symptoms: $\square$ Immediately after extraction \\ $\square 24$ hours after extraction \\ $\square 48$ hours after extraction \\ $\square 72$ hours after extraction \\ $\square$ others, specify \\ Treatment provided: $\square$ Irrigation with normal saline \\ $\square$ Packing with Alvogyl \\ $\square$ Medications,}

Fig. (2). Questionnaire used for subjects with a dry socket.

Table 1. Summary of the Medical History of the Study Population

\begin{tabular}{|l|c|c|}
\hline \multicolumn{1}{|c|}{ Medical History } & Number of patients & Percentage (\%) \\
\hline \hline None & 566 & 70.3 \\
\hline Diabetes Mellitus (DM) & 25 & 3.1 \\
\hline Hypertension (HT) & 19 & 2.6 \\
\hline Ischemic heart disease & 5 & 0.6 \\
\hline Asthma & 4 & 0.5 \\
\hline DM and HT & 30 & 3.6 \\
\hline Chronic Bronchitis & 15 & 1.9 \\
\hline Previous Surgery & 30 & 3.7 \\
\hline Rheumatoid Arthritis & 13 & 1.6 \\
\hline Psychological disorders & 12 & 1.5 \\
\hline Anemia & 5 & 0.6 \\
\hline Peptic ulcer & 26 & 3.2 \\
\hline Osteoporosis & 5 & 0.6 \\
\hline Hepatitis & 21 & 2.6 \\
\hline Renal stones & 10 & 1.2 \\
\hline Hyperthyroidism & 3 & 0.4 \\
\hline Epilepsy & $\mathbf{8 0 5}$ & 0.3 \\
\hline Migraine & & 1.4 \\
\hline Prosthetic heart valve & Total & 0.3 \\
\hline & 3 & \\
\hline
\end{tabular}

Table 2. Medications Used Regularly by the Study Population Before the Extraction

\begin{tabular}{|l|c|c|}
\hline \multicolumn{1}{|c|}{ Medication } & No. of patients & Percentage (\%) \\
\hline \hline None & 636 & 79 \\
\hline NSAID's & 25 & 3 \\
\hline Paracetamol & 20 & 2.5 \\
\hline Antihypertensive drugs & 18 & 2.2 \\
\hline Hypoglycemic agents & 15 & 1.9 \\
\hline Warfarin & 20 & 2.5 \\
\hline Salbutamol & 5 & 0.6 \\
\hline Antidepressant drugs & 7 & 0.9 \\
\hline Sodium valproate & 8 & 1 \\
\hline Oral contraceptives & 25 & 3.1 \\
\hline Insulin & 18 & 2.3 \\
\hline H2-blockers & 5 & 0.6 \\
\hline Ferrous sulphate & 3 & 0.4 \\
\hline
\end{tabular}

Upper anterior teeth and posterior teeth constituted 217 $(16.7 \%)$ and $379(28 \%)$ of the total number of extractions, respectively, whereas lower anterior teeth and lower posterior teeth constituted $198(15.2 \%)$ and $510(39.1 \%)$ of the total number of extractions, respectively. A total of 118 (91\%) extractions were non-surgical (1046 (80\%) simple elevations and $142(10.9 \%)$ root separations), while 117 (9\%) teeth needed surgical extraction (47 (3.6\%) needed a flap with bone removal and $70(5.4 \%)$ needed only a flap without bone removal). 
Undergraduate students carried out 1158 extractions (88.7\%), (347 (26.5\%) by fourth year students, $811(62.2 \%)$ by fifth year students), while clinical dental officers CDOs and consultants carried out $78(6 \%)$ and $69(5.3 \%)$ extractions (Table 3 ).

Advanced caries was the commonest cause of extraction leading to the extraction of $566(41.2 \%)$. This was followed by periodontal disease which led to 314 (23.9\%) extractions. In addition, pericoronitis and orthodontic treatment formed the indications for the extraction of $102(7.9 \%)$ and $40(6 \%)$ teeth, respectively. Only $30(2.3 \%)$ teeth were extracted because of a missing opposing tooth (Table 4).

A total of 162 mandibular third molars were extracted, of which 32 (56.6\%) were impacted and needed surgical extraction.

All teeth were extracted under local anesthesia. Infiltration around the tooth (labial/ buccal and lingual/ palatal) was used in $804(56.1 \%)$ extractions, while regional block anesthesia (inferior dental/ lingual and mental block) was used in $501(43.9 \%)$ extractions.

All patients received oral postoperative instructions by the operators. Post-extraction medications were prescribed for 192 patients. Pain killers (ibuprofen and/ or paracetamol) were prescribed alone for 97 patients, whereas a combination of antibiotics (either amoxicillin or metronidazole or both) and pain killers was prescribed for 95 patients.

\section{Prevalence of Dry Socket}

The overall incidence of dry socket was 3.2\% (40 dry sockets in 1305 extractions). Some patients developed more

Table 3. Distribution of Teeth According to the Operator

\begin{tabular}{|l|c|c|}
\hline \multicolumn{1}{|c|}{ Operator } & No. of teeth & Percentage (\%) \\
\hline \hline $4^{\text {th }}$ Year Student & 347 & 26.5 \\
\hline $5^{\text {th }}$ Year Student & 811 & 62.2 \\
\hline Clinical Dental Officer & 78 & 6 \\
\hline Consultant & 69 & 5.3 \\
\hline \multicolumn{1}{|c|}{ Total } & $\mathbf{1 3 0 5}$ & $\mathbf{1 0 0 \%}$ \\
\hline
\end{tabular}

Table 4. Distribution of Teeth According to the Cause of Extraction

\begin{tabular}{|l|c|c|}
\hline \multicolumn{1}{|c|}{ Reason for extraction } & No. of teeth & Percentage (\%) \\
\hline \hline Advanced caries & 566 & 41.2 \\
\hline Periodontal disease & 314 & 23.8 \\
\hline $\begin{array}{l}\text { Advanced caries and periodontal } \\
\text { disease }\end{array}$ & 253 & 19.3 \\
\hline Pericorinitis & 102 & 7.8 \\
\hline Orthodontic treatment & 40 & 6 \\
\hline Missing opposing tooth & 30 & 2 \\
\hline \multicolumn{1}{|c|}{ Total } & $\mathbf{1 3 0 5}$ & $\mathbf{1 0 0 \%}$ \\
\hline
\end{tabular}

than one dry socket, which made the overall incidence per patient $6.4 \%$ (30 patients with dry sockets out of 469 patients who had extractions). In addition, dry socket incidence (per tooth) following non-surgical extraction of teeth was $1.7 \%$ (20 of 1188), while that following surgical extraction was $12 \%$ (14 of 117). This difference was statistically significant $(\mathrm{p}<0.002)$ (Fig. 3).

Patients were grouped into single-extraction cases (302) and multiple extraction cases (167). The incidence of dry socket in the first group was $7.3 \%$ (22 of 302), while in the second group it was $3.4 \%$ (18 of 536). This difference was statistically significant $(\mathrm{P}=0.018)$ (Fig. 4).

The incidence of dry socket was 5.1\% (23 dry sockets in 422 extractions) following extractions in smokers compared to $2.1 \%$ (17 dry sockets in 833 extractions) in non-smokers. This difference was statistically significant $(\mathrm{P}=0.001)$ (Fig. 5).

There was no statistically significant association between the development of dry socket and patient's age, sex, medical history, medications (preoperative or postoperative), indications for extraction, operator experience, and amount and technique of local anesthesia.

Patients who developed dry socket were 16 (53\%) males and $14(47 \%)$ females. The incidence of dry socket in female patients was $3.9 \%$ (14 dry sockets in 359 extractions) compared to $2.5 \%$ (26 dry sockets in 1040 extractions) in male patients. This difference was statistically insignificant $(p=0.671)$.

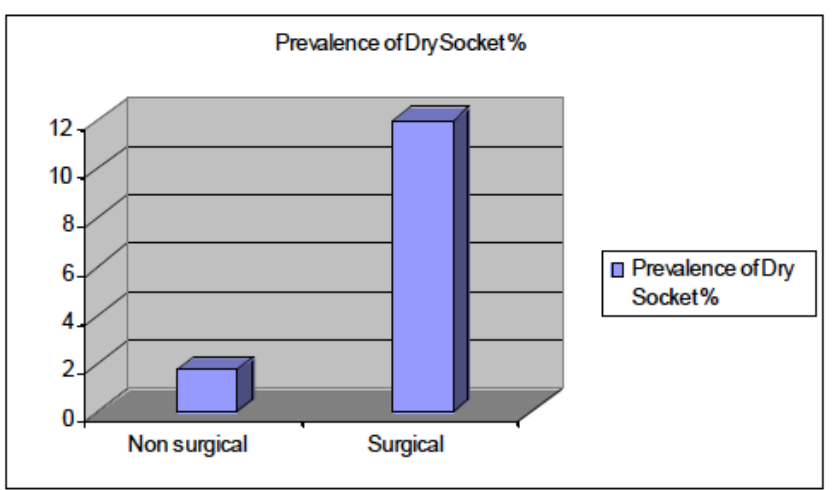

Fig. (3). Distribution of dry socket prevalence according to surgical vs non surgical extraction.

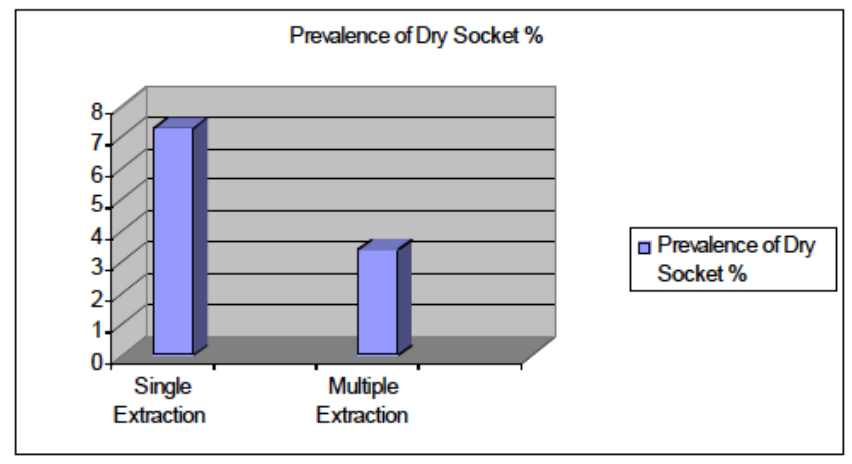

Fig. (4). Prevalence of dry socket following single and multiple extractions. 


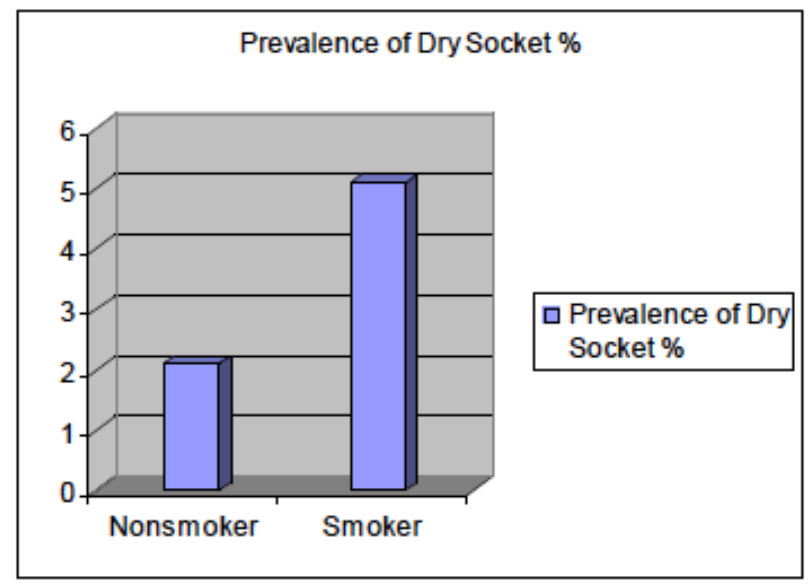

Fig. (5). Prevalence of dry socket in relation to smoking.

The peak incidence of dry socket was in the 18 to 33 year age group and was $4.8 \%$ (21 dry sockets in 438 extractions) compared to $2.9 \%$ ( 7 dry sockets in 241 extractions) in patients whose ages ranged from 34 to 49 years and 1.6\% (12 dry sockets in 750 extractions) in patients who were older than 50 years. None of the patients under 18 years of age developed dry sockets. This difference was statistically insignificant $(\mathrm{p}=0.201)$ (Fig. 6).

Regarding surgical technique and surgical experience, the incidence of dry socket was found to be $1.8 \%$ (21 of 1167) and $1.2 \%$ (1 of 83 ) following non-surgical extractions performed by undergraduate and postgraduate students, respectively. This difference was statistically insignificant $(p=$ $0.677)$.

\section{DISCUSSION}

Dry socket is an important clinical complication. It is characterized by severe pain starting after two or three days of extraction. The etiology of this complication is an increased local fibrinolysis leading to breakdown of the clot [10]. Some antifibrinolytic agents, when placed topically in the extraction site, have been shown to reduce the occurance of dry socket [25]. Surgical trauma and bacterial infections remain the acceptable initiating factors of this fibrinolytic activity [10].

The results of this study show the prevalence of dry socket at the Dental Teaching Center/ Al-Quds University

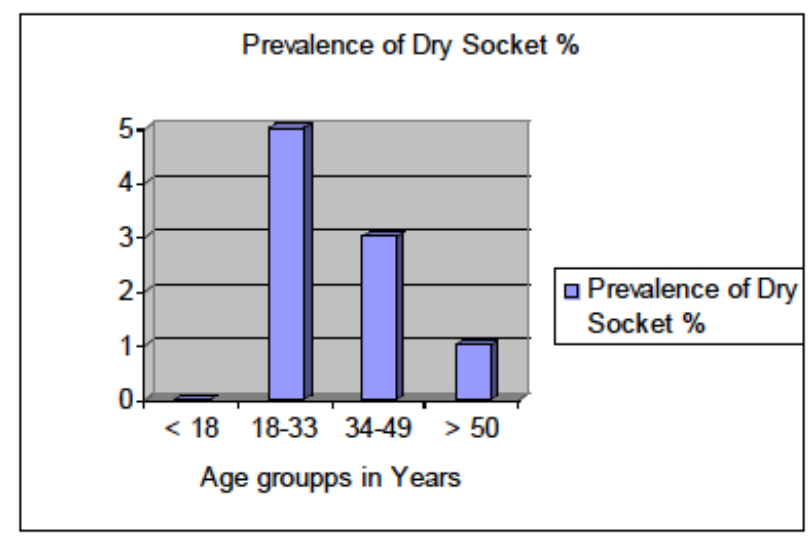

Fig. (6). Distribution of dry socket incidence in different age groups. and its clinical features are generally similar to those reported in the literature. The overall prevalence of dry socket was $3.2 \%$.

The increase in extraction difficulty leads to increase in the prevalence of dry socket $[10,12,22]$. This is attributable to more liberation of direct tissue activators secondary to bone marrow inflammation following the more difficult and, hence, more traumatic extractions [10]. In the current study surgical extractions were associated with a significantly higher incidence of dry socket $(12 \%)$, which supports what is documented in the literature in which trauma is considered as a contributing factor in the pathogenesis of dry socket.

Single versus multiple extractions is considered a factor that increases the prevalence of dry socket. Previous studies $[4,12]$ showed the prevalence of dry socket was higher after single extractions than multiple extractions, and this was consistent by the results of the current study in which dry socket prevalence was $7.3 \%$ following single extractions and $3.4 \%$ following multiple extractions. Multiple extractions are generally simple because they are performed on mobile and periodontally compromised teeth. Krough [26] recommended if several adjacent teeth are to be extracted, it is better to perform in one operation.

In this present study the difference in the prevalence of dry socket between males $(2.5 \%)$ and females $(4.3 \%)$ was statistically insignificant. This finding coincides with the study perfomed by Al Khateeb et al. [11] and contradicts the results of several studies $[3,4,12,27]$. MacGreoger ${ }^{12}$ reported a higher incidence of dry socket in females with a male: female ratio of $2: 3$. The possible explanation of this difference can hide behind the fact that eastern societies differ from western ones in smoking habit between females and males. In western societies females smoke in a higher percentage than in eastern societies. The present study shows that the percentage of of female smokers was much less than males (3.4\% and 58\% respectively).

It is worth mentioning that the use of oral contraceptives is a factor the raises the prevalence of dry socket among female patients. The use of contraceptives thought to be the reason behind the increased susceptibility of females to dry socket $[1,24,27]$ was minimal in this study. However, timing of dental extraction according to menstrual cycle is a predisposing factor in the occurrence of dry socket [28].

The results of this study also showed the prevalence of dry socket to be highest in third and fourth decades of life with a peak incidence in the 18-33 year age group which is in agreement with results of many researches $[3,4,6,11$, 12]. The possible explanation for this age dependence is still unknown, but the presence of well developed alveolar bone and the relative infrequency of periodontal diseases at this age (both make tooth extraction more difficult) may provide a possible explanation. ${ }^{4}$ Most surgical extractions in this study were performed in this age group, and surgical extractions are associated with a higher incidence of dry socket.

The results of this study contradicts the findings of Johnson and Blanton, [29] who showed no significant difference in the prevalence of dry socket between smokers and nonsmokers, a dose dependent relationship between smoking and the occurrence of dry socket was demonstrated in the 
present study which is similar to the findings of other studies $[14,30]$.

Failure to follow postoperative instructions is behind the increased prevalence of dry socket among smokers. It has been reported patients who smoked on the same day of surgery had a higher incidence of dry socket than those who smoked on the second day postoperatively [30]. Whether a systemic mechanism or a direct local effect (heat and suction) on the extraction site is responsible for this increase in the occurrence of dry socket is unclear.

\section{CONCLUSIONS}

From the results of this study, the following conclusions can be made:

1. The incidence of dry sockets following single extractions was significantly higher than that following multiple extractions.

2. There was a statistically significant difference in the incidence of dry socket between smokers and nonsmokers.

3. The incidence of dry socket was higher following surgical extractions than following non-surgical extractions.

4. There was no statistically significant association between the development of dry socket and patient's age, sex, medical history, medications (preoperative or postoperative), indication for extraction, extraction site, and operator's experience.

\section{REFERENCES}

[1] Lilly GE, Osborn DB, Rael EM, Samuels HS, Jones JC. Alveolar osteitis associated with mandibular third molar extractions. J Am Dent Assoc 1974; 88: 802-6.

[2] Alexander RE. Dental extraction wound management: a case against medicating post-extraction sockets. J Oral Maxillofac Surg 2000; 58: 538-51.

[3] Amaratunga NA, Senaratane CM. A clinical study of dry socket in Sri Lanka. Br J Oral Maxillofac Surg 1988; 26: 410-18.

[4] Field EA, Speechley JA, Rotter E, Scott J. Dry socket incidence compared aftera 12-year interval. Br J Oral Maxillofac Surg 1985; 23: 419-27.

[5] Jaffar N, Nor GM. The prevalence of post-extraction complications in an outpatient dental clinic in kuala lumpor malaysia- a retrospective survey. Singapore Dent J 2000; 23(1): 24-8.

[6] Oginni FO, Fatusi OA, Algabe AO. A clinical evaluation of dry socket in a nigerian teaching hospital. J Oral Maxillofac Surg 2003; 61(8): 871-6.

[7] Bloomer CR. Alveolar osteitis prevention by immediate placement of medicated packing. Oral Surg Oral Med Oral Pathol Oral Radiol Endod 2000; 90: 282-4.
[8] Petri WH, Wilson TM. Clinical evaluation of antibiotic supplemented bone allograft. J Oral Maxillofac Surg 1992; 51: 982-7.

[9] Erickson RT, Wait DE, Wilkison RH. A study of dry sockets. Oral Surg 1960; 13: 1046-50.

[10] Birn H. Etiology and pathogenesis of fibrinolytic alveolitis (' dry socket'). Int J Oral Surg 1973; 2: 215-63.

[11] Al- Khateeb TL, El-Marsafi AI, Butler NP. The relationship between the indications for the surgical removal of impacted third molars and the incidence of alveolar osteitis. J Oral Maxillofac Surg 1991; 49: 141-5.

[12] MacGregor AJ. Aetiology of dry socket: a clinical investigation. $\mathrm{Br}$ J Oral Surg 1968; 6: 49-58.

[13] Catellani JE, Harvey S, Erickson SH, Cherkink D. Effect of oral contraceptive cycle on dry socket (localized alveolar osteitis). J Am Dent Assoc 1980; 101: 777-80.

[14] Sweet JB, Butler DP. The relationship of smoking to localized osteitis. J Oral Surg 1979; 37: 732-5.

[15] Meechan JG, Venchard GR, Rogers SN, et al. Local anesthesia and dry socket: a clinical investigation I of single ectractions in male patients. Int J Oral Maxillofac Surg 1987; 16: 279-84.

[16] Krekmanov L. Alveolitis after operative removal of third molar in the mandible. Int J Oral Surg 1981; 10: 173-9.

[17] Rood JP, Murgatroid J. Metronidazole in the prevention of 'dry socket'. Br J Oral Surg 1979; 17: 62-70.

[18] Ritzau M, Swangsilpa K. The prophylactic use of propylic ester of p-hydrobenzoic acid on alveolitis sicca dolorosa. Oral Surg Oral Med Oral Pathol Radiol Endod 1977; 43: 32-7.

[19] Sweet JB, Macynaki AA. Effect of antimicrobial mouthrinses on the incidence of localized alveolitis and infection following mandibular third molar surgery. Oral Surg Oral Med Oral Pathol 1985; 59: 24-6.

[20] Field EA, Nind D, Varga E, Martin MV. The effect of chlorhexidine irrigation on the incidence of dry socket: A pilot study. Br J Oral Maxillofac Surg 1988; 26: 395-401.

[21] Ragno JR, Szkutnik AJ. Evaluation of $0.12 \%$ chlorhexidine rinse on the prevention of alveolar osteitis. Oral Surg Oral Med Oral Pathol 1991; 72: 524-6.

[22] Blum IR. Contemporary views on dry socket (alveolar osteitis): a clinical appraisal of standardization, aetiopathogenesis and management: a critical review. Int J Oral Maxillofac Surg 2002; 31: 309-17.

[23] Vezeau PJ. Dental extraction wound management: medicating postextraction sockets. J Oral Maxillofac Surg 2000; 58: 531-7.

[24] Fazakerley M, Field EN. Dry socket: a painful post-extraction complication: a review. Dental Update 1991; 18: 31-4.

[25] Ritzua M, Therkildsen P. Antifibrinolytic prevention of alveolitis sicca dolorsa. Int J Oral Surg 1978; 7: 534-40.

[26] Krogh HW. Incidence of dry socket. J Am Dent Assoc 1937; 24 : 1829-36.

[27] Sweet JB, Bulter DP. Predisposing and operative factors: effect on the incidence of localized osteitis in mandibular third molar surgery. Oral Surg Oral Med Oral Pathol 1978; 46: 206-15.

[28] Oginni FO. Dry socket: a preoperative study of prevalent risk factors in a nigerian population. J Oral Maxillofac Surg 2008; 66: 2290-5.

[29] Johnson WS, Blanton EE. An evaluation of 9-aminoacridine/ gelfoam to reduce dry socket formation. Oral Surg Oral Med Oral Pathol 1988; 66: 167-70.

[30] Al-Belasy FA. The relationship of "Shisha" (water pipe) Smoking to postextraction dry socket. J Oral Maxillofac Surg 2004; 62: 1014.

This is an open access article licensed under the terms of the Creative Commons Attribution Non-Commercial License (http://creativecommons.org/licenses/by-nc/3.0/) which permits unrestricted, non-commercial use, distribution and reproduction in any medium, provided the work is properly cited. 